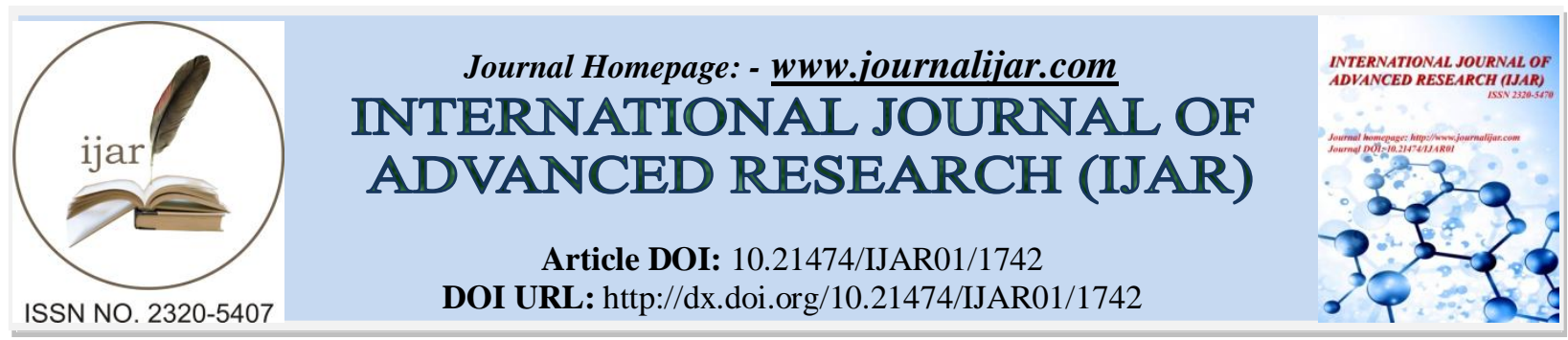

RESEARCH ARTICLE

\title{
A STUDY ON PERSONAL HYGIENE AMONG RURAL WOMEN IN PERAMBALUR DISTRICT.
}

\section{T. Geetha ${ }^{1}$ and Dr. G. Metillda Buvaneshwari ${ }^{2}$.}

1. Ph.D. Scholar, Assistant Professor in Social Work, Thanthai Hans Roever College (Autonomous), Perambalur.

2. Assistant Professor in Social Work, Cauvery College for Women, Trichy.

\section{Manuscript Info}

Manuscript History

Received: 12 July 2016

Final Accepted: 23 August 2016

Published: September 2016

Key words:-

Personal Hygiene, Health.

\begin{abstract}
The present study understands the personal hygiene among rural women. Health is a basic requirement to improve the quality of life. Women are engaged in various responsibilities of domestic work, look after the family members and livestock. Personal hygiene is one of the predominant one to protect from many kind of diseases. One of the most effective ways we have to protect ourselves and others from illness is good personal hygiene. Women are getting wider knowledge in health aspects but they are failed to practice it most of the time. $86 \%$ percentage of the respondents had no toilet facilities at their home only open air defection. $56 \%$ percentage of the respondents had oral health problems. Below half of the respondents (24\%) are used tobacco. The aim of this study is to describe the personal hygiene among rural women. The researcher has adopted descriptive design.
\end{abstract}

Copy Right, IJAR, 2016,. All rights reserved.

\section{Introduction:- \\ Hygiene:-}

Hygiene is a set of practices performed for the preservation of health. According to the World Health Organization (WHO), "Hygiene refers to conditions and practices that help to maintain health and prevent the spread of diseases".

Rural Women are active agents of economic and social change and environmental protection who are, in many ways and to various degrees, constrained in their roles as farmers, producers, investors, caregivers and consumers. Lifestyle and personal health choices also affect the health and expected longevity of individuals in rural areas.

\section{Review of literature:-}

1. Khondker Saif Imtiaz, Khadiza Begum, Nilufar Begum, Samiha Naureen, Jony Barua, Jobaer Faruque, Abdur Rahman Khalid (2014),:-

Made study on "Practice of personal hygiene among rural women of a selected community in Bangladesh". Good health is a marker of good economic status of a nation. Personal hygiene should be maintained first for obtaining great accuracy in work, low suffering from diseases and to reduce possibility of diseases. This study was undertaken to assess practice of personal hygiene among rural women of a selected community in Bangladesh. A descriptive type of cross sectional study was conducted during March-June 2012. 150 women of various ages selected from Garibpur and Tangurpur villages of Jessore District to assess two basic components of personal hygiene, hand washing and safe drinking water. Non probability convenient sampling technique was followed and 
data were collected by face to face interview using pre tested, self administered, semi structured questionnaire. The mean age of the respondents was 33 years. Regarding educational qualification, $87.33 \%$ were educated in different levels and $12.67 \%$ were illiterate. Occupational status revealed majority $(74.67 \%)$ of them were housewives. Regarding economic condition, most $(60 \%)$ of the respondents had family income <10,000 Taka. In this study, majority (87.34\%) had practiced hand washing before eating. Among them on taking different types of food $(86.26 \%)$ practiced hand washing before taking meals only $13.74 \%$ before taking breakfast and none of the respondents washed hands before taking any dry food. Majority (95.34\%) practiced hand washing after defecation, among them (82\%) used soap, $16 \%$ used ash and $2 \%$ used soil after defecation. In this study, majority (90.67\%) used tube well which was not marked red, $6 \%$ used pond and $3.33 \%$ used river as their source of drinking water. Good practice of personal hygiene and use of safe drinking water has significant importance to lead a healthy life, the villagers of Bangladesh should be well motivated regarding this aspect by regular health education programmes.

2. K. Mallikharjuna Rao, N. Balakrishna, N. Arlappa, A. Laxmaiah and G.N.V. Brahmam (2012):-

The study made on Diet and Nutritional Status of Women in India. The health of women is linked to their status in the society. The demographic consequence of the women has formed expression in various forms, such as female infanticide, higher death rate, lower sex ratio, low literacy level and lower level of employment of women in the non-agricultural sector as compared to men. Generally, at household level, cultural norms and practices and socioeconomic factors determine the extent of nutritional status among women. National Nutrition Monitoring Bureau has been carrying out regular surveys on diet and nutritional status of different population groups since 1972. For the purpose of present investigation, the data collected during 1998-99 and 2005-06 on diet and nutritional status of tribal and rural population respectively in nine States of India was utilized. The intake of all the foods except for other vegetables and roots and tubers was lower than the suggested level among rural as well as tribal women. The study revealed inadequate dietary intake, especially micronutrient deficiency (hidden hunger) during pregnancy and lactation. The prevalence of goiter was relatively higher (4.9\%) among tribal women compared to their rural counterparts $(0.8 \%)$. Tribal women were particularly vulnerable to under nutrition compared to women in rural areas. The prevalence of chronic energy deficiency was higher (56\%) among tribal NPNL women compared to rural women $(36 \%)$.

\title{
3. Rajiv Ranjan Karn, Buna Bhandari, Nilambar Jha, (2011):-
}

Conducted $a$ study on personal hygiene and sanitary practices in a rural village of Mornag District of Nepal. Inadequate sanitation has direct effect on health of individual, family, communities and nation as a whole. To assess the personal hygiene and sanitary condition of the Katahari Village Development Committee (VDC). The cross sectional study was done in Katahari VDC of Morang district. A total of 80 households were randomly selected from two wards of VDC. The data were collected by interview method using interview schedule. Data were entered in Excel sheet and analyzed on SPSS program. Many respondents (61\%) were unable to read and write, $33 \%$ involved in private job in various factory. Knowledge of sanitation was high (90\%) but only $65 \%$ of them were using soap water for hand washing. Sixty percent had no toilet facilities. There was significant association between education and toilet facilities among community people. Land holding and type of family had no significant association with toilet facilities. The knowledge regarding sanitation was high among community people but very poor in practice.

4. Sisko Honkala, Jassem Al-Ansari, (2005), in a Self-reported oral health, oral hygiene habits, and dental attendance of pregnant women in Kuwait, in the Journal of Clinical periodontology.

The aim of the study was to describe self-reported oral health, oral hygiene habits, and frequency of visits to a dentist among pregnant women in Kuwait. A cross-sectional study with an anonymous structured questionnaire was distributed among 650 pregnant women during May-June 2003, when they were admitted to the maternity ward at the largest government maternity hospital in Kuwait City. The response rate was 93\% ( $n=603)$. Result of the study was every fourth respondent was in her first pregnancy, while $36 \%$ already had three or more children. Every fifth woman felt that her oral health was poor, and one-third of the women believed that they had periodontal problems currently. About two-thirds of the women were brushing more than once a day and almost all (94\%) at least once a day. Over the previous 6 months, $40 \%$ had experienced dental pain. Half of the women had visited a dentist during pregnancy, mostly for dental pain. Most of the women had received no instructions concerning oral health care during their pregnancy. A large proportion of the pregnant women in this study had oral health problems; however, half of the women had not seen a dentist during their pregnancy.

\author{
Methodology of the study:- \\ Objectives:- \\ * To study the socio-economic details of the rural women. \\ * To know the knowledge of personal hygiene among rural women.
}


* To find out the food intake among the rural women.

* To provide the suitable suggestions to enhance their personal health.

\section{Research design:-}

The researcher used to descriptive research design in this study. This study was described the characteristics of socio-economic condition, family system, knowledge of personal hygiene, and, food practice of the rural women

Universe:-

Women from below poverty line in Mettupalayam village at Perambalur district was consider as universe.

\section{Sampling method:-}

The researcher has selected 50 women from Mettupalayam village by following simple random sampling, Lottery method.

\section{Tool of data collection:-}

The researcher used self prepared interview schedule was as a tool for data collection. The interview schedule was consisted these aspects like, socio-economic condition, family system, knowledge of personal hygiene, and, food practice of the rural women.

\section{Findings and suggestion:-}

- Below half of the respondents (44\%) are belongs to the age group of 29-38.

- Majority of the respondents $(96 \%)$ are Hindus.

- Majority of the respondents (92\%) are SC.

- 88 percentage of the respondents was married and living with husband.

- More than half of the respondents (52\%) are studied up to primary school.

- Most of the respondents (84\%) occupation was Agriculture.

- Majority of the respondents (92\%) type of family was nuclear family.

- More than half of the respondents (64\%) are living with 5-7 members in their family.

- Below half of the respondents (44\%) are earned monthly below Rs.5,000 to 10,000.

- $62 \%$ percentage of the respondents lived in a Pucca house.

- $82 \%$ percentage of the respondents fetched water from public tap nearby house.

- $58 \%$ percentage of the respondents had debt.

- $52 \%$ percentage of the respondents got loan for agriculture purpose.

- Most of the respondents (78\%) are got knowledge regarding balanced diet.

- Majority of the respondents (92\%) are not took balanced diet in their daily food.

- $64 \%$ percentage of the respondents ate fruits, green leaves, and, egg in monthly once.

- $72 \%$ percentage of the respondents added non-vegetarian in their food monthly once.

- Below half of the respondents (34\%) felt pre menopause syndromes.

- Below half of the respondents (24\%) are used tobacco.

- 45 percentage of the respondents are not having oral health problems.

- $76 \%$ percentage of the respondent did not practised home hygiene (wash vegetables before cook, clean in domestic work)

- $46 \%$ percentage of the respondent are not practised the hand hygiene (clean nail, when coughing and sneezing)

- $68 \%$ percentage of the respondents were cooked one time at morning so, the length of time, appropriate temperature of the food was not good.

- $84 \%$ percentage of the respondent did not keep their bathrooms clean.

- $56 \%$ percentage of the respondents not interested in self-groomed due the cultural background. 
DISTRIBUTION OF RESPONDENT BY AREAS OF PERSONAL HYGIENE AT HOME

\begin{tabular}{|c|l|c|c|}
\hline S. No. & \multicolumn{1}{|c|}{ Areas of personal hygiene at home } & $\begin{array}{c}\text { No. of } \\
\text { Respondents } \\
(\mathrm{n}=50)\end{array}$ & $\begin{array}{c}\text { Percentage } \\
(100 \%)\end{array}$ \\
\hline 1 & Home hygiene (wash vegetables before cook, clean in domestic work) & 12 & 24 \\
& Yes & 38 & 76 \\
& No & & \\
\hline 2 & Hand hygiene (clean nail, when coughing and sneezing) & 44 \\
& Yes & 22 & 46 \\
\hline 2 & No & 28 & 32 \\
& Yood hygiene (length of time, appropriate temperature) & 16 & 68 \\
\hline 3 & No & 34 & \\
& Hygiene in bathroom & 8 & 16 \\
& Yes & & 84 \\
\hline
\end{tabular}

\section{Suggestions:-}

\section{Good personal hygiene habits include:-}

- Washing the body often for refreshment, feel fresh, and avoid tiredness. So, take bath twice is best way of keeping our body clean.

- Should clean the teeth once a day. Brushing the teeth after each meal is the best way to avoid gum disease and tooth decay is avoided. Washing the hair with soap or shampoo at least once a week

- Washing hands with soap after going to the toilet.

- Washing hands with soap before preparing and during eating food in our daily activities, such as working and playing, disease causing germs may get onto the hands and under the nails.

- Use clean cloth after every bath.

- Dry clothes in the sun to dry. The sun's rays will kill some disease-causing germs and parasites

- Turning away from other people and covering the nose and mouth with a tissue or the hand when coughing or sneezing.

\section{Family Management:-}

When there are too many people in any house, the likelihood of them getting disease is greater than if the house is not overcrowded. This is because people in an overcrowded house will be much closer to each other and it is therefore easier for any germs to spread from one to another. For example:

- Sneezing and coughing in crowded rooms makes it easier to spread cold and flu germs

- Sharing towels can spread trachoma germs and other germs which cause eye infections (runny or sore eyes)

- Several children sleeping in the same bed makes it easier to spread a scabies infection

- Mouth will be spread in the air and other people can breathe them in, or the droplets can get onto food

\section{Conclusion:-}

This study concludes that the practice of personal hygiene among rural women in Mettupalayam village was not appreciated one. The women are well known about the hygiene practice but not willing to follow certain things due to their attitude. Most of the women are studied up to primary school and engaged in Agriculture. In rural areas the type of family was nuclear family and consist 5-7 members. Because of male preference society and the impact of cultural practice they had more than 2 children. The family monthly income was below Rs.5,000 to 10,000. Women are described as Goddesses, Power and everything but they did not allow eating proper food in their meal. Show less interest in getting knowledge regarding self-care, and, nutritious intake. Among the poor, rural women are the poorest and more vulnerable in the Indian society. Education is played a vital role and the eye opener many rural women to access health care, personal care, and utilize the public care to protect and prevent them from diseases. Healthy women can head a healthy family and healthy Nation. 


\section{Reference:-}

1. Khondker Saif Imtiaz, Khadiza Begum, Nilufar Begum, Samiha Naureen, Jony Barua,

2. Jobaer Faruque, Abdur Rahman Khalid (2014),

3. K. Mallikharjuna Rao, N. Balakrishna, N. Arlappa, A. Laxmaiah and G.N.V.

4. Brahmam (2012). Diet and Nutritional Status of Women in India, Journal of Human Ecology Vol. 29(3): 165170 (2010).

5. https://en.wikipedia.org/wiki/Hygiene

6. https://www.betterhealth.vic.gov.au/health/conditionsandtreatments/personal-hygiene 